\title{
Stability and survival analysis of elderly patients with osteolytic spinal bone metastases after palliative radiotherapy
}

\section{Results from a large multicenter cohort}

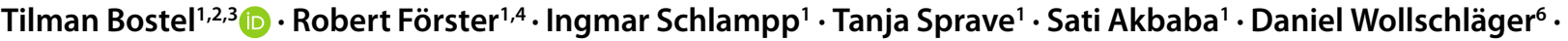 \\ Jürgen Debus ${ }^{1,2}$ - Arnulf Mayer ${ }^{3}$ Heinz Schmidberger ${ }^{3} \cdot$ Harald Rief $^{1}$ - Nils Henrik Nicolay ${ }^{1,2,5}$
}

Received: 2 January 2019 / Accepted: 3 June 2019 / Published online: 25 June 2019

(c) The Author(s) 2019

\section{Abstract}

Purpose This retrospective study aimed to evaluate the stability and fracture rates of osteolytic spinal bone metastases (SBM) in elderly patients following palliative radiotherapy (RT) and to derive prognostic factors for stability and survival. Methods A total of 322 patients aged at least 70 years received palliative RT at two major German academic medical centers or at the German Cancer Research Center. Stability assessment was based on the validated Taneichi score prior to RT and at 3 and 6 months after RT. The survival time following RT was assessed, and prognostic factors for stability and survival were analyzed.

Tilman Bostel, M.D.

tilman.bostel@unimedizin-mainz.de

Robert Förster

robert.foerster@usz.ch

Ingmar Schlampp

ingmar.schlampp@med.uni-heidelberg.de

Tanja Sprave

tanja.sprave@med.uni-heidelberg.de

Sati Akbaba

sati.akbaba@med.uni-heidelberg.de

Daniel Wollschläger

wollschlaeger@uni-mainz.de

Jürgen Debus

juergen.debus@med.uni-heidelberg.de

Arnulf Mayer

arnulf.mayer@unimedizin-mainz.de

Heinz Schmidberger

heinz.schmidberger@unimedizin-mainz.de
Harald Rief

harald.rief@med.uni-heidelberg.de

Nils Henrik Nicolay

nils.nicolay@uniklinik-freiburg.de

1 Department of Radiation Oncology, University Hospital of Heidelberg, Im Neuenheimer Feld 400, 69120 Heidelberg, Germany

2 Clinical Cooperation Unit Radiation Oncology, German Cancer Research Center (DKFZ), Im Neuenheimer Feld 280, 69120 Heidelberg, Germany

3 Department of Radiation Oncology, University Medical Center Mainz, Langenbeckstraße 1, 55131 Mainz, Germany

4 Department of Radiation Oncology, University Hospital of Zurich, Raemistraße 100, 8091 Zurich, Switzerland

5 Department of Radiation Oncology, University Hospital of Freiburg, Robert-Koch-Straße 3, 79106 Freiburg, Germany

6 Institute of Medical Biostatistics, Epidemiology and Informatics (IMBEI), University Medical Center Mainz, Mainz, Germany 
Results Prior to RT, 183 patients (57\%) exhibited unstable SBM and 68 patients (21\%) pathological fractures. At 3 and 6 months after RT, significant recalcification and stabilization were evident in 19\% (23/118) and 40\% (31/78) of surviving patients, respectively. Only 17 patients $(5 \%)$ experienced new pathological fractures following RT. Tumor histology was found to significantly influence stabilization rates with only breast cancer patients exhibiting increased stabilization compared to patients with other histologies. The median survival time and 6-month survival rates following RT were 5.4 months (95\% confidence interval 4.4-7.2 months) and 48\%, respectively. The patients' performance status was found to be the strongest predictor for survival after RT in this patient cohort; further factors demonstrating a significant association with survival were the application of systemic treatment, the number of SBM and the primary tumor histology. To analyze the influence of age on survival after RT, study patients were stratified into 3 age groups (i.e., 70-74 years, 75-79 years, and $\geq 80$ years). The subgroup of patients aged at least 80 years showed a strong trend towards a worse survival time following RT compared to younger patients (i.e., 6-month survival rate $39 \%$ vs. $51 \%$; $p=0.06$, log-rank test).

Conclusions Prognostic factors influencing overall survival such as performance status and histology should guide the choice for palliative RT for SBM. Strongly hypofractionated RT regimes may be advisable for most elderly patients considering the overall poor prognosis in order to reduce hospitalization times.

Keywords Neoplasm metastases $\cdot$ Spine $\cdot$ Geriatrics $\cdot$ Fracture $\cdot$ Aged

\section{Stabilitäts- und Überlebensanalyse geriatrischer Patienten mit osteolytischen spinalen Knochenmetastasen nach palliativer Radiotherapie}

Ergebnisse einer großen multizentrischen Kohorte

\section{Zusammenfassung}

Hintergrund In dieser retrospektiven Analyse wurden osteolytische spinale Knochenmetastasen von geriatrischen Patienten nach palliativer Radiotherapie (RT) hinsichtlich der Stabilisierungs- und Frakturraten untersucht, zudem wurden prognostische Faktoren für Stabilität und Überleben analysiert.

Methoden Insgesamt 322 Patienten mit einem Alter von mindestens 70 Jahren wurden an zwei deutschen Universitätskliniken oder am Deutschen Krebsforschungszentrum (DKFZ) mit einer palliativen RT behandelt und im Rahmen der Studie analysiert. Die Stabilität wurde anhand des validierten Taneichi-Scores vor RT sowie 3 und 6 Monate nach RT beurteilt. Die Überlebenszeit nach RT wurde erfasst und prognostische Faktoren bezüglich Stabilität und Überleben analysiert.

Ergebnisse Vor RT wiesen 183 Patienten (57\%) instabile Knochenmetastasen und 68 Patienten (21\%) pathologische Frakturen auf. Nach 3 und 6 Monaten zeigten sich bei 19\% (23/118) und 40\% (31/78) der überlebenden Patienten eine signifikante Rekalzifikation und Stabilisierung. Neue pathologische Frakturen wurden nach RT bei 17 Patienten (5\%) nachgewiesen. Die Tumorhistologie hatte signifikanten Einfluss auf die Stabilisierungsraten, wobei Patienten mit Mammakarzinom höhere Stabilisierungsraten als Patienten mit anderen Tumorentitäten erzielten. Das mediane Überleben und die 6-Monats-Überlebensrate nach RT betrugen 5,4 Monate (95\%-Konfidenzintervall 4,4-7,2 Monate) und 48\%. Der stärkste Prädiktor für das Überleben nach RT war der Allgemeinzustand (AZ) der Patienten; weitere Faktoren, die einen signifikanten Zusammenhang mit dem Überleben nach RT zeigten, waren die Verabreichung einer Systemtherapie, die Anzahl der Knochenmetastasen und der histologische Befund des Primärtumors. Um den Einfluss des Alters auf die Überlebenszeit nach RT zu analysieren, erfolgte eine Stratifikation der Studienpatienten in 3 Altersgruppen (70-74 Jahre, 75-79 Jahre und $\geq 80$ Jahre). Dabei zeigte sich für die Patienten mit einem Alter von mindestens 80 Jahren ein starker Trend hin zu einer schlechteren Überlebenszeit nach RT als bei jüngeren Patienten (6-Monats-Überlebensrate 39\% vs. $51 \% ; p=0,06$ Log-Rang-Test).

Schlussfolgerungen Prognostische Faktoren für das Überleben, wie der AZ und die Tumorhistologie, sollten bei der Wahl der palliativen RT von instabilen Knochenmetastasen beachtet werden. In Anbetracht der meist schlechten Prognose empfiehlt sich für die meisten geriatrischen Patienten die Anwendung stark hypofraktionierter Bestrahlungsprotokolle, um unnötige Hospitalisierungszeiten zu vermeiden.

Schlüsselwörter Metastasen · Wirbelsäule $\cdot$ Geriatrie $\cdot$ Fraktur · Ältere Patienten 


\section{Background}

Improvements in general health care and oncologic advances have resulted in strongly increasing numbers of geriatric cancer patients [1]. However, due to restrictions in the performance status, prevalent comorbidities or poor treatment tolerance, general therapy guidelines often do not apply to these elderly patients, requiring dedicated trials [2].

Spinal bone metastases (SBM) from solid tumors affect a considerable number of patients and are of particular concern for geriatric patients, as they may more easily result in immobilization and dependence on full-time care [3]. Additionally, relevant comorbidities such as osteoporosis are more prevalent in the elderly and may increase the risk of SBM-related impairments such as pathological fractures [4].

Palliative radiotherapy (RT) constitutes a mainstay in the treatment of SBM and aims at reducing pain and supporting recalcification, resulting in improved bone stability [5, 6]. RT dose and fractionation are commonly adjusted depending on the extent of metastatic disease, comorbidities, performance status, and estimated life expectancy [7-13]. The influence of palliative RT on the analgesic effects and improvements in neurological deficits have already been subject to previous investigations $[9,10,12]$. However, the benefit of RT for the recalcification and stabilization of initially unstable SBM in geriatric patients is still largely unknown. A deeper understanding of these treatment effects of RT will be relevant to choose appropriate treatment algorithms with regard to treatment time and dose.

Therefore, this retrospective study aimed to assess osteolytic SBM in a large multicenter cohort of elderly patients over 70 years regarding stability, fracture rates before and after RT, survival, and prognostic factors for stability and survival.

\section{Patients and methods}

\section{Patient selection}

The medical records of 322 elderly patients with SBM treated with palliative RT at the University Hospitals of Heidelberg and Mainz and the German Cancer Research Center were retrospectively assessed. Patient data from cancer registries of participating centers were collected to include patients aged 70 years or older receiving palliative RT for SBM between March 2000 and January 2014. The diagnosis of SBM was based on imaging procedures such as computed tomography (CT), magnetic resonance imaging (MRI) or bone scintigraphy. Inclusion criteria of this analysis were an age $\geq 70$ years, an osteolytic phenotype of SBM and location of metastases in the thoracic or lumbar spine.

\section{Stability assessment}

To assess the stability of osteolytic SBM, the validated Taneichi bone stability score was based on the planning CT scans and two consecutive follow-up CT scans conducted at 3 months (follow-up 1) and 6 months (follow-up 2) after RT. The applied scoring system is based on purely radiological criteria and is therefore a simple method for classifying osteolytic SBM in stable and unstable lesions [14]. For all patients included in this dataset, stability assessments were performed by a board-certified radiologist: Osteolytic SBM were rated on a scale from $A$ to $\mathrm{G}$ based on radiological risk factors such as the degree of vertebral body tumor affectation, costovertebral joint or pedicle destruction. Based on previous experiences and publications, type $\mathrm{A}$ to $\mathrm{C}$ lesions were classified as stable and type $\mathrm{D}$ to $\mathrm{G}$ lesions as unstable (Fig. 1; $[5,6,15])$. In the case of multiple osteolytic lesions per vertebral body, only the most severe lesion was scored. In $57 \%$ of the patients, the planning target volume (PTV) comprised more than one tumor affected vertebral body.

\section{Treatment}

For all patients, RT was planned based on planning CTs and performed over one or several $6 \mathrm{MV}$ photon fields. The PTV included the vertebral body/bodies affected by the metastatic spread and the neighboring ones in the cranial and caudal directions. The most common fractionation scheme was $10 \times 3 \mathrm{~Gy}$, followed by $5 \times 4 \mathrm{~Gy}$ and $20 \times 2 \mathrm{~Gy}$ (Table 1). The indication for palliative RT was individually determined based on disease stage and the patients' performance status. None of the study patients received additional surgery or other invasive procedures. Further information concerning additional nonsurgical treatments is provided in Table 1.

\section{Statistical analysis}

Overall survival was defined as the period from start of RT until death from any cause and estimated with the Kaplan-Meier method. Multivariate Cox regression analysis was performed to evaluate possible predictors of overall survival. The distribution of the Taneichi score over time was determined using Bowker's test; McNemar test was used to assess the distribution of a stable vs. unstable Taneichi score. Univariate ordinal logistic regression analysis was conducted to detect factors associated with the Taneichi score at 3 and 6 months after radiation treatment. Statistical analysis was done using $\mathrm{R}$ software, version 3.5.1 (R Core Team 2018, Vienna, Austria). $P$-values $<0.05$ were considered statistically significant. The Institutional Review Boards at Heidelberg and Mainz Medical Centers approved this study (S-513/2012). 
a
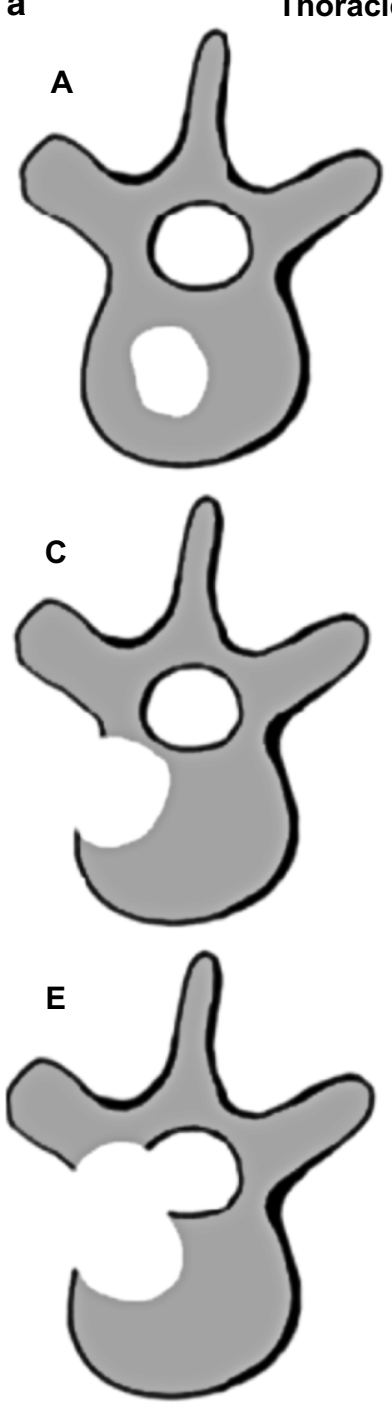
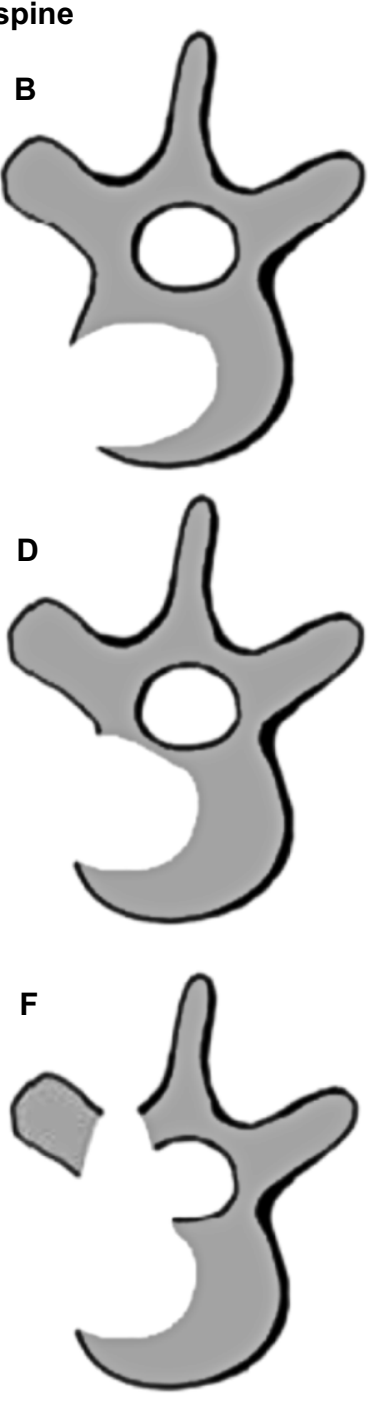

b

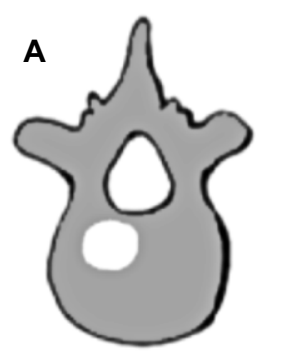

Lumbar spine
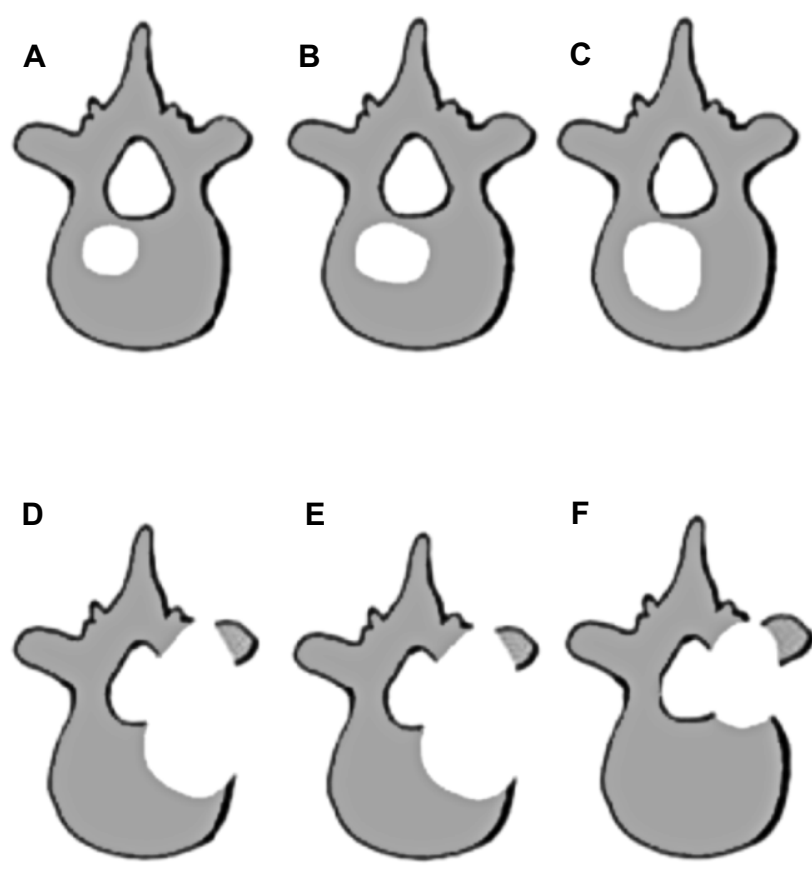

E
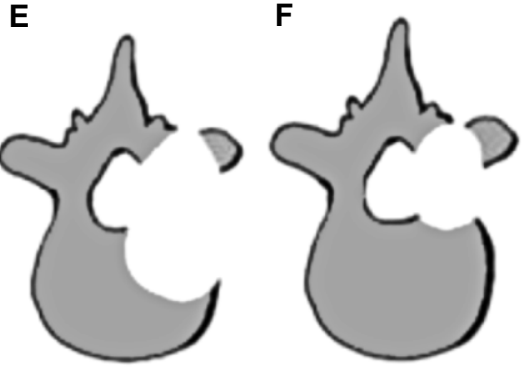

\begin{tabular}{lcccccc}
\hline & A & B & C & D & E & F \\
\cline { 2 - 7 }$\%$ TO & 30 & 60 & 30 & 60 & 30 & 60 \\
$\begin{array}{l}\text { Costovertebral joint } \\
\text { destruction }\end{array}$ & - & - & + & + & + & + \\
$\begin{array}{l}\text { Pedicle destruction } \\
\begin{array}{l}\text { Posterior elements } \\
\text { destruction }\end{array}\end{array}$ & - & - & - & - & + & + \\
$\begin{array}{l}\text { Predicted probability } \\
\text { of collapse }\end{array}$ & 0.13 & 0.68 & 0.57 & 0.96 & 0.71 & 0.98 \\
\hline
\end{tabular}

\begin{tabular}{lccccccc} 
& A & B & C & D & E & F & G \\
\cline { 2 - 8 } & 20 & 30 & 40 & 40 & 60 & 5 & 20 \\
Pedicle destruction & - & - & - & + & + & + & + \\
$\begin{array}{l}\text { Posterior elements } \\
\text { destruction }\end{array}$ & - & - & - & - & - & + & + \\
$\begin{array}{l}\text { Predicted probability } \\
\text { of collapse }\end{array}$ & 0.07 & 0.25 & 0.60 & 0.99 & 0.99 & 0.06 & 0.38 \\
\hline
\end{tabular}

Fig. 1 a Taneichi score of the thoracic spine, b Taneichi score of the lumbar spine TO Percentage of metastatic bone destruction in the vertebral body. (Modified from [19])

\section{Results}

The median survival time of the study population after palliative RT of SBM was 5.4 months (95\% confidence interval [CI] 4.4-7.2 months). In total, 322 patients presented with a total of 935 osteolytic SBM (range, 1-13 metastases per patient). The baseline characteristics of the study patients are summarized in Table 1.

\section{Stability analysis}

Most patients exhibited unstable SBM prior to RT according to the Taneichi score (i.e., subtypes D-G; 57\%, 
Table 1 Patients' and treatment characteristics

\begin{tabular}{|c|c|c|}
\hline Characteristics & Value & Percent \\
\hline \multicolumn{3}{|l|}{$\overline{\text { Age (years) }}$} \\
\hline Median & 75.3 & - \\
\hline Range & $70.1-88.4$ & - \\
\hline \multicolumn{3}{|l|}{ Gender (n) } \\
\hline Female & 141 & 43.8 \\
\hline Male & 181 & 56.2 \\
\hline \multicolumn{3}{|l|}{ Karnofsky PS (\%) } \\
\hline 90 & 18 & 5.6 \\
\hline 80 & 82 & 25.5 \\
\hline 70 & 115 & 35.7 \\
\hline 60 & 78 & 24.2 \\
\hline 50 & 21 & 6.5 \\
\hline 40 & 7 & 2.2 \\
\hline 30 & 1 & 0.3 \\
\hline \multicolumn{3}{|l|}{ Number of spinal bone metastases ( $n$ ) } \\
\hline Median & 2 & - \\
\hline Range & $1-13$ & - \\
\hline Solitary & 140 & 43.5 \\
\hline Multiple & 182 & 56.5 \\
\hline \multicolumn{3}{|l|}{ Spine involvement ( $n$ ) } \\
\hline Thoracic & 199 & 61.8 \\
\hline Lumbar & 123 & 38.2 \\
\hline \multicolumn{3}{|l|}{ Primary tumor $(n)$} \\
\hline Breast carcinoma & 47 & 14.6 \\
\hline NSCLC & 117 & 36.3 \\
\hline SCLC & 11 & 3.4 \\
\hline Renal carcinoma & 53 & 16.5 \\
\hline Colorectal cancer & 33 & 10.2 \\
\hline Prostate cancer & 13 & 4.0 \\
\hline Urothelium carcinoma & 21 & 6.5 \\
\hline $\mathrm{HCC}$ & 2 & 0.6 \\
\hline ACC (head and neck) & 2 & 0.6 \\
\hline HNSCC & 3 & 0.9 \\
\hline Vulvar carcinoma & 2 & 0.6 \\
\hline Ovarian cancer & 2 & 0.6 \\
\hline Uterine cancer & 2 & 0.6 \\
\hline Malignant melanoma & 14 & 4.3 \\
\hline Distant extraskeletal metastases ( $n$ ) & 120 & 37.3 \\
\hline Brain & 30 & 9.3 \\
\hline Lung & 67 & 20.8 \\
\hline Liver & 63 & 19.6 \\
\hline Skin & 18 & 5.6 \\
\hline \multicolumn{3}{|l|}{ Single radiation dose (Gy) } \\
\hline Median & 3 & - \\
\hline Range & $2-4$ & - \\
\hline \multicolumn{3}{|l|}{ Cumulative dose (Gy) } \\
\hline Median & 30 & - \\
\hline Range & $8-40$ & - \\
\hline
\end{tabular}

Table 1 (Continued)

\begin{tabular}{lll}
\hline Characteristics & Value & Percent \\
\hline Fractionation of RT $(n)$ & 1 & \\
$1 \times 8$ Gy & 3 & 0.3 \\
$5 \times 4$ Gy & 3 & 0.9 \\
$10 \times 2$ Gy & 230 & 71.4 \\
$10 \times 3$ Gy & 1 & 0.3 \\
$12 \times 3$ Gy & 27 & 8.4 \\
$14 \times 2.5$ Gy & 57 & 17.7 \\
$20 \times 2$ Gy & & \\
Indications for $R T(n)$ & 272 & 84.5 \\
Pain & 209 & 64.9 \\
Instability & 8 & 2.5 \\
Neurologic deficit & 144 & 44.7 \\
Chemotherapy $(n)$ & & \\
Other treatments for bone metastases $(n)$ & 149 & 46.3 \\
Orthopedic corset & 186 & 57.8 \\
Bisphosphonates &
\end{tabular}

Karnofsky PS Karnofsky performance score; $n$ number; $R T$ radiotherapy; Gy Gray; NSCLC non-small cell cancer; $S C L C$ small cell cancer; $H C C$ hepatic cell cancer; $A C C$ adenoid cystic carcinoma; $H N S C C$ head and neck squamous cell cancer

$n=183$ ), and $75 \%$ of those patients initially presented with associated pain symptoms $(n=138)$. During the followup period, RT stabilized primary unstable bone lesions in $13 \%(n=23 / 183)$ and $17 \%(n=31 / 183)$ of the patients as assessed at the first and second follow-up, respectively ( $p<0.001$ for each follow-up, McNemar's test). When referring only to the patients with unstable SBM still alive at follow-up 1 and 2, the corresponding stabilization rates were 19\% (23/118) and 40\% (31/78), respectively. Only 1 out of 139 patients with initially stable SBM was observed with a deterioration of stability and was classified unstable in both follow-up examinations. The Bowker test showed significant departure from symmetry in the joint distribution pattern of the scored Taneichi subtypes prior to irradiation and at both follow-up examinations (Tables 2 and 3) $(p<0.001$ at both follow-ups). At 6 months after palliative RT, highest stabilization rates of primary unstable osteolytic SBM were seen in breast cancer patients (Table 4). In contrast, patients with osteolytic SBM from poorly represented tumor entities in our study population such as malignant melanoma, hepatic cell cancer (HCC), head and neck cancers, gynecologic and genitourinary malignancies mainly exhibited a very poor outcome in terms of stabilization (Table 4). Univariate ordinal logistic regression at follow-up 1 and 2 revealed that several factors correlated with a significant negative stabilization probability of initially unstable SBM after palliative RT compared to breast cancer histologies, among them the presence of pathological fractures before the initiation of RT, lung cancer histology or histology of the group of poorly rep- 
Table 2 Test of symmetry for Taneichi score (1st follow-up)

\begin{tabular}{|c|c|c|c|c|c|c|c|c|c|}
\hline \multicolumn{10}{|c|}{ Subtypes at follow-up 1} \\
\hline & & A & B & $\mathrm{C}$ & $\mathrm{D}$ & $\mathrm{E}$ & $\mathrm{F}$ & G & Total \\
\hline \multirow[t]{8}{*}{ Subtypes before RT } & $A$ & 24 & 1 & 0 & 0 & 0 & 0 & 0 & 25 \\
\hline & $B$ & 3 & 23 & 2 & 0 & 0 & 0 & 0 & 28 \\
\hline & $C$ & 0 & 2 & 34 & 1 & 0 & 0 & 0 & 37 \\
\hline & $D$ & 2 & 1 & 6 & 18 & 0 & 0 & 0 & 27 \\
\hline & $E$ & 3 & 0 & 4 & 1 & 42 & 2 & 0 & 52 \\
\hline & $F$ & 0 & 1 & 4 & 1 & 1 & 27 & 0 & 34 \\
\hline & $G$ & 2 & 0 & 0 & 0 & 0 & 2 & 1 & 5 \\
\hline & Total & 34 & 28 & 50 & 21 & 43 & 31 & 1 & 208 \\
\hline
\end{tabular}

This Bowker test shows the distribution of subtypes of Taneichi score prior to RT and at the first follow-up examination after RT. The evaluation of the distribution of subtypes A to G shows in $16 \%$ of the study patients $(n=33)$ an improvement of stability over the course of time. Deterioration of stability occurs only in $3 \%$ of the patients $(n=6)$, while in the majority of patients who were still alive at the first follow-up examination $(81 \%$, $n=169)$ no change of the stability is evident

$R T$ radiotherapy

Table 3 Test of symmetry for Taneichi score (2nd follow-up)

\begin{tabular}{|c|c|c|c|c|c|c|c|c|c|}
\hline \multicolumn{10}{|c|}{ Subtypes at follow-up 2} \\
\hline & & A & $\mathrm{B}$ & $\mathrm{C}$ & $\mathrm{D}$ & $\mathrm{E}$ & $\mathrm{F}$ & G & Total \\
\hline \multirow[t]{8}{*}{ Subtypes before $R T$} & $A$ & 18 & 1 & 0 & 0 & 0 & 0 & 0 & 19 \\
\hline & $B$ & 5 & 17 & 2 & 0 & 0 & 0 & 0 & 24 \\
\hline & $C$ & 4 & 5 & 22 & 1 & 0 & 0 & 0 & 32 \\
\hline & $D$ & 6 & 0 & 7 & 7 & 0 & 0 & 0 & 20 \\
\hline & $E$ & 4 & 2 & 5 & 0 & 19 & 2 & 0 & 32 \\
\hline & $F$ & 0 & 1 & 4 & 0 & 0 & 16 & 0 & 21 \\
\hline & $G$ & 2 & 0 & 0 & 0 & 0 & 2 & 1 & 5 \\
\hline & Total & 39 & 26 & 40 & 8 & 19 & 20 & 1 & 152 \\
\hline
\end{tabular}

This Bowker test shows the distribution of subtypes of Taneichi score prior to RT and at the second follow-up examination after RT. The evaluation of the distribution of subtypes A to G shows in $31 \%$ of the study patients $(n=47)$ an improvement of stability over the course of time. Deterioration of stability occurs only in $4 \%$ of the patients $(n=6)$, while in the majority of patients who were still alive at the second follow-up examination $(65 \%, n=99)$ no change of the stability is evident

$R T$ radiotherapy

Table 4 Tumor entity specific stabilization rates of primary unstable osteolytic SBM

\begin{tabular}{lll}
\hline Tumor entity & Stabilization rate at FU1 & Stabilization rate at FU2 \\
\hline Breast cancer & $27 \%(8 / 30)$ & $53 \%(10 / 19)$ \\
Lung cancer & $21 \%(12 / 57)$ & $42 \%(16 / 38)$ \\
NSCLC & $23 \%(12 / 53)$ & $42 \%(16 / 38)$ \\
SCLC & $0 \%(0 / 4)$ & $\mathrm{NA}$ \\
Renal cancer & $22 \%(2 / 9)$ & $29 \%(2 / 7)$ \\
Colorectal cancer & $14 \%(1 / 7)$ & $40 \%(2 / 5)$ \\
HCC & $0 \%(0 / 2)$ & $0 \%(0 / 1)$ \\
HNSCC & $0 \%(0 / 1)$ & $\mathrm{NA}$ \\
ACC & $0 \%(0 / 1)$ & $\mathrm{NA}$ \\
Malignant melanoma & $0 \%(0 / 2)$ & $0 \%(0 / 2)$ \\
Uterine cancer & $0 \%(0 / 1)$ & $100 \%(1 / 1)$ \\
Vulvar cancer & $0 \%(0 / 1)$ & $\mathrm{NA}$ \\
Prostate cancer & $0 \%(0 / 2)$ & $0 \%(0 / 1)$ \\
Urothelial cancer & $0 \%(0 / 5)$ & $0 \%(0 / 4)$ \\
\hline
\end{tabular}

SBM Spinal Bone Metastases; FU Follow-up; NA not analyzable (i.e., patient had died), NSCLC non-small cell cancer; SCLC small cell cancer; $H C C$ hepatic cell cancer; $A C C$ adenoid cystic carcinoma; $H N S C C$ head and neck squamous cell cancer 
Table 5 Analysis of prognostic factors related to stabilization of initially unstable SBM

\begin{tabular}{|c|c|c|c|c|c|c|}
\hline \multirow[b]{2}{*}{ Predictor } & \multicolumn{3}{|c|}{ 1st follow-up } & \multicolumn{3}{|c|}{ 2nd follow-up } \\
\hline & $p$-value & OR & $\mathrm{CI}$ & $p$-value & OR & $\mathrm{CI}$ \\
\hline Age & 0.243 & 1.05 & $0.968-1.140$ & 0.224 & 1.05 & $0.970-1.140$ \\
\hline $\begin{array}{l}\text { Poorly represented cancers }{ }^{\mathrm{a}} \\
\text { (vs. breast cancer) }\end{array}$ & 0.016 & 4.29 & $1.309-14.090$ & 0.021 & 3.47 & $1.209-9.970$ \\
\hline $\begin{array}{l}\text { Colorectal cancer } \\
\text { (vs. breast cancer) }\end{array}$ & 0.388 & 1.92 & $0.435-8.520$ & 0.815 & 0.86 & $0.244-3.030$ \\
\hline $\begin{array}{l}\text { Renal cancer } \\
\text { (vs. breast cancer) }\end{array}$ & 0.476 & 1.69 & $0.398-7.210$ & 0.167 & 2.90 & $0.640-13.130$ \\
\hline $\begin{array}{l}\text { Lung cancer } \\
\text { (vs. breast cancer) }\end{array}$ & 0.048 & 2.33 & $1.009-5.370$ & 0.029 & 2.48 & $1.096-5.630$ \\
\hline $\begin{array}{l}\text { KPS } \\
(<70 \% \text { vs. } \geq 70 \%)\end{array}$ & 0.551 & 1.01 & $0.977-1.040$ & 0.464 & 0.99 & $0.956-1.020$ \\
\hline $\begin{array}{l}\text { Chemotherapy } \\
\text { (yes vs. no) }\end{array}$ & 0.723 & 1.13 & $0.567-2.270$ & 0.821 & 0.93 & $0.483-1.780$ \\
\hline $\begin{array}{l}\text { Location } \\
\text { (thoracic vs. lumbar spine) }\end{array}$ & 0.526 & 1.26 & $0.613-2.600$ & 0.829 & 1.08 & $0.555-2.080$ \\
\hline $\begin{array}{l}\text { Number of SBM } \\
(1 \mathrm{vs} .>1)\end{array}$ & 0.906 & 1.01 & $0.880-1.160$ & 0.426 & 1.06 & $0.921-1.210$ \\
\hline $\begin{array}{l}\text { Extraskeletal metastases } \\
\text { (yes vs. no) }\end{array}$ & 0.206 & 1.67 & $0.755-3.700$ & 0.648 & 1.18 & $0.582-2.390$ \\
\hline $\begin{array}{l}\text { Bisphosphonates } \\
\text { (yes vs. no) }\end{array}$ & 0.662 & 1.18 & $0.556-2.520$ & 0.182 & 1.63 & $0.797-3.310$ \\
\hline $\begin{array}{l}\text { Fractures before RT } \\
\text { (yes vs. no) }\end{array}$ & 0.037 & 2.81 & $1.066-7.40$ & 0.026 & 2.72 & $1.127-6.58$ \\
\hline
\end{tabular}

KPS Karnofsky performance score, OR Odds Ratio, CI Confidence limits of the results for a confidence level of $95 \%, S B M$ Spinal bone metastases, $R T$ Radiotherapy

a Included SBM of following tumor entities: malignant melanoma, adenoid cystic carcinoma (ACC), hepatic cell cancer (HCC), head and neck squamous cell cancer (HNSCC), ovarian cancer, uterine cancer, vulvar cancer, urothelial cancer, prostate cancer

resented tumors (summarized in Table 5). The chance for reaching stabilization and re-ossification in patients with unstable SBM and a KPS below $70 \%$ was relatively poor (5\%; 3/65) compared to those patients with a KPS of $70 \%$ and above $(24 \% ; 28 / 118)$. Pathological fractures were commonly diagnosed prior to RT $(21 \%$; $n=68)$, while postRT fractures including increasing sintering of previously collapsed vertebrae were evident in only $5 \%$ of patients $(n=17)$. In $94 \%$ of those post-RT fractures (16/17), SBM were initially rated unstable.

\section{Survival analysis}

For the complete patient cohort, relatively poor survival was evident after palliative RT. Overall survival rates 3, 6 and 12 months after RT amounted to $66 \%$ (95\% CI 61-72\%), $48 \%$ (95\% CI $43-54 \%$ ) and $29 \%$ (95\% CI 24-34\%); the median survival following RT was 5.4 months (95\% CI 4.4-7.2 months).

To analyze the association of age with overall survival, we stratified the study patients into 3 age groups (i.e., 70-74 years, 75-79 years and $\geq 80$ years) and found a strong tendency towards worse survival after RT for patients $\geq 80$ years, albeit not reaching statistical significance
( $p=0.06$; Fig. 2). The corresponding median overall survival was 7.6 months (95\% CI 4.8-9.0 months) for patients aged 70-74 years, 5.0 months (95\% CI 3.6-9.2 months) for patients aged 75-79 years and 4.3 months $(95 \% \mathrm{CI}$ 3.2-6.3 months) for patients aged 80 years or older.

In comparing overall survival for patients with the 4 most common primary tumor histologies (i.e., breast, renal, colorectal and lung cancer) accounting for $81 \%$ of the study population (261/322 patients), we found significantly better survival rates for breast cancer patients and a significantly worse prognosis for lung and colorectal cancer patients ( $p=0.003$; Fig. 3$)$.

Using multivariate analyses, KPS was found to be the strongest predictive factor for overall survival after RT $(p<0.001$, multivariate Cox regression analysis; Table 6). In patients with KPS $<70 \%$, median overall survival was only 1.8 months (95\% CI 1.6-2.3 months) compared to 9.1 months (95\% CI 7.6-10.5 months) for patients with KPS $\geq 70 \%$ ( $p<0.001$; Fig. 4). Furthermore, the number of SBM, the application of chemotherapy and a tumor histology from the pooled group of poorly represented entities were significant prognostic factors in the multivariate analysis (Table 6). In patients with only 1 SBM, median overall survival reached 7.4 months (95\% CI 5.4-9.2 months) 
Fig. 2 Kaplan-Meier estimation of overall survival depending on the patients' age showing a strong trend towards a worse overall survival for patients aged at least 80 years $(p=0.06$, log-rank test)
Fig. 3 Kaplan-Meier estimation of overall survival depending on the histology of the primary tumor showing a significantly reduced prognosis for lung and colorectal cancer patients compared to breast cancer patients $(p=0.003, \log$-rank test $)$
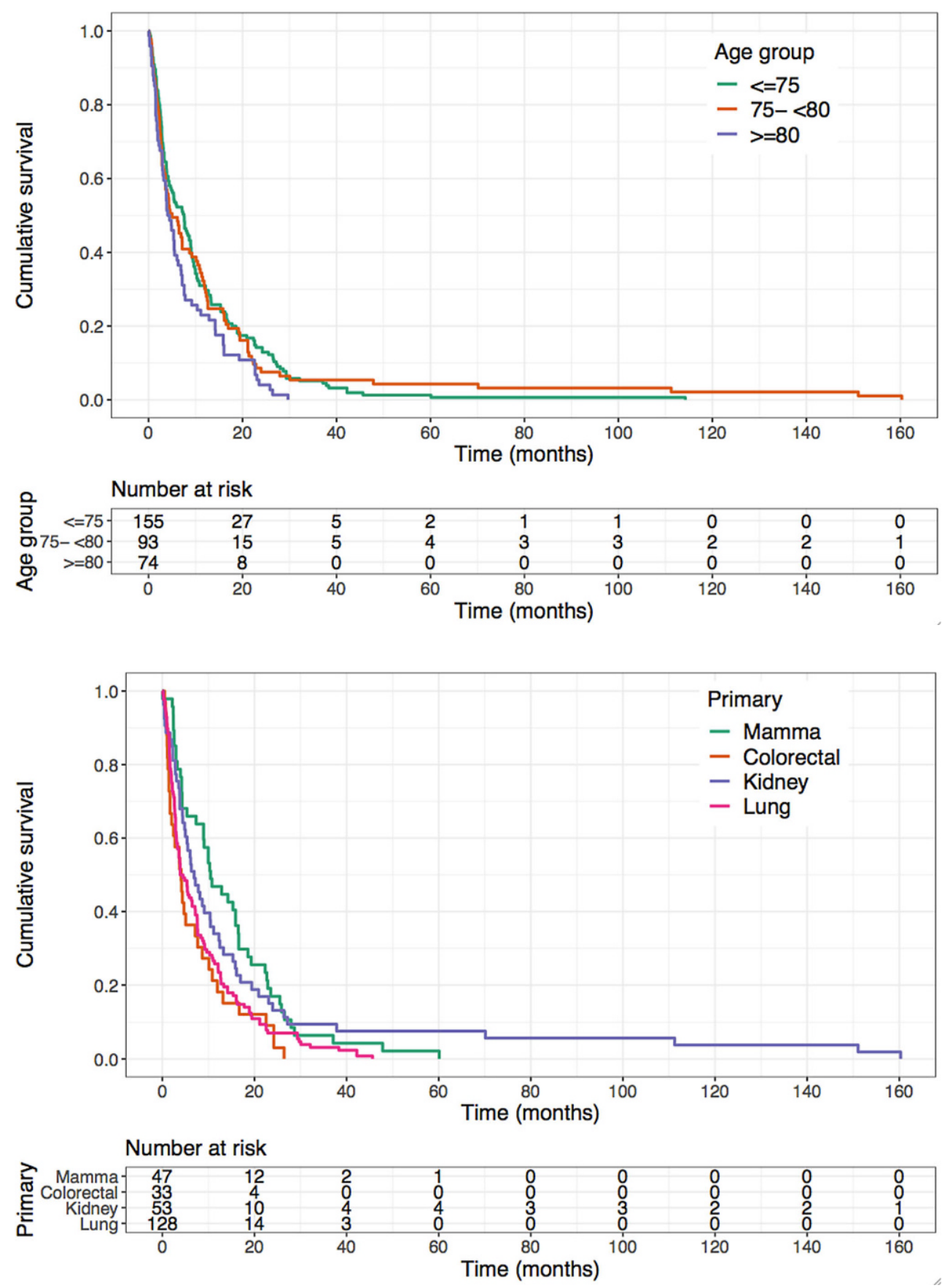

compared to 3.9 months (95\% CI 3.3-6.3 months) in those patients with more than 1 SBM $(p=0.029$; Fig. 5). Administration of chemotherapy extended median overall survival from 4.9 months (95\% CI 3.9-7.2 months) to 5.8 months (95\% CI 4.4-8.7 months; $p=0.046$ ).

In the univariate analysis, the only further predictive factor associated with a poor overall survival was tumor histology, with lung and colorectal cancer histologies correlating with a reduced survival (Table 6). Patients' age, the prevalence of additional extraskeletal metastases, the location of SBM, the concurrent administration of bisphosphonates and the presence of pathological fractures prior to RT were not statistically significant predictors of overall survival (Table 6).

\section{Discussion}

While the analgesic effect of RT on bone metastases has already been well investigated, there is a lack of study data concerning the stabilizing effect of RT on unstable osteolytic metastases [12]. In recent years, we and other groups 
Fig. 4 Kaplan-Meier estimation of overall survival depending on the performance score showing a significantly improved prognosis for patients with a Karnofsky performance score (KPS) of at least $70 \%$ compared to patients with a KPS $<70 \%(p<0.001$, log-rank test $)$

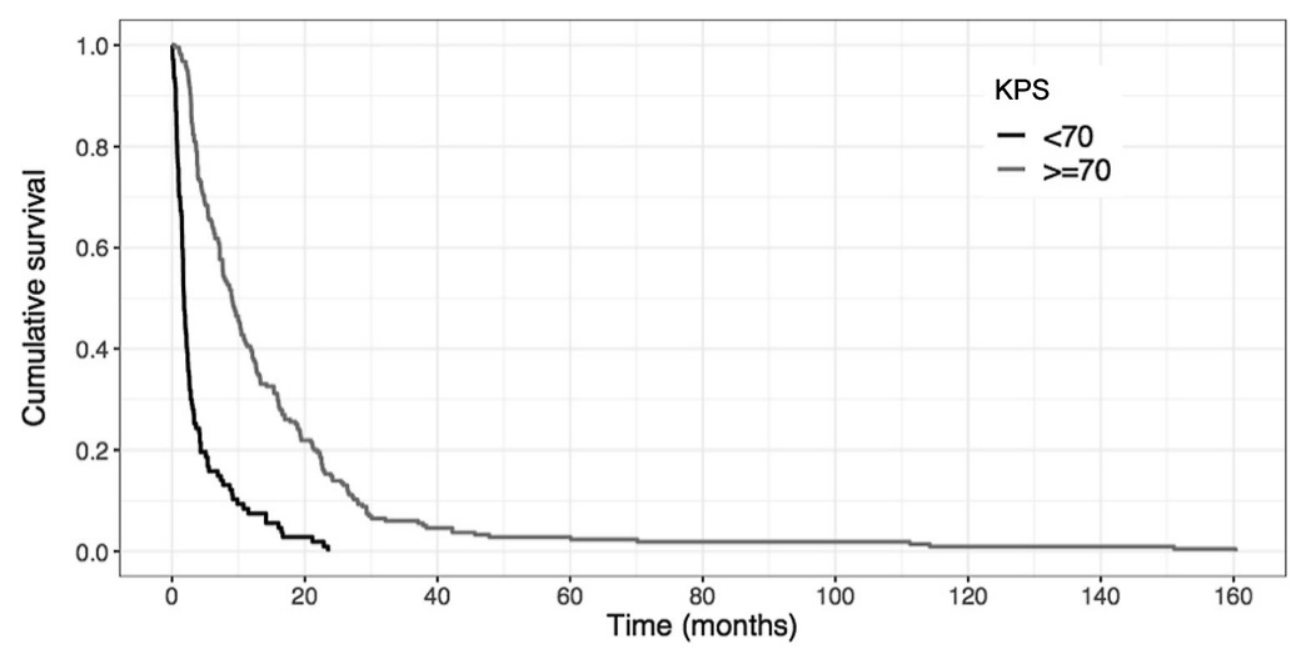

Number at risk

\begin{tabular}{|c|c|c|c|c|c|c|c|c|c|}
\hline \multirow{3}{*}{$\begin{array}{l}\omega \\
\tilde{x}>70 \\
\underline{x}>=70\end{array}$} & 107 & 3 & 0 & 0 & 0 & 0 & 0 & 0 & 0 \\
\hline & 215 & 47 & 10 & 6 & 4 & 4 & 2 & 2 & 1 \\
\hline & 0 & 20 & 40 & 60 & $\begin{array}{r}80 \\
\text { (me }\end{array}$ & 100 & 120 & 140 & 160 \\
\hline
\end{tabular}

Fig. 5 Kaplan-Meier estimation of overall survival depending on the number of spinal bone metastases (SBM) showing a significantly improved prognosis for patients with only 1 SBM compared to patients with at least 2 SBM $(p=0.029, \log$-rank test)
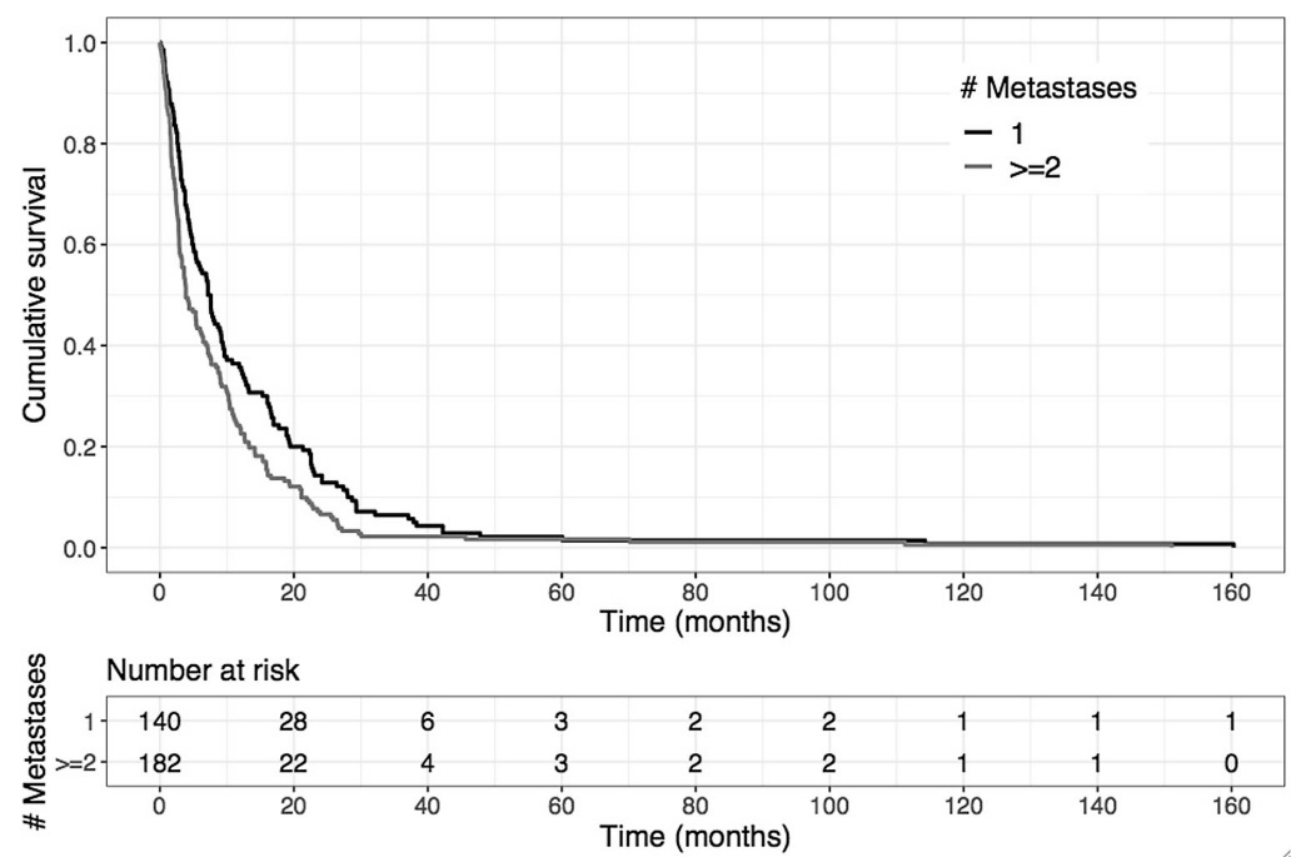

focused on assessment of the remineralization process of osteolytic SBM after RT [16]. As a result, we found substantial differences of recalcification and stabilization rates of initially unstable SBM depending on the histology [5, 6, $15,17-19]$. Also in this dataset, tumor histology was found strongly associated with differing stabilization rates after palliative RT, and stabilization rates may correspond to individual radiation sensitivities of various tumor cell types, although the exact underlying mechanism regulating radiation-induced recalcification of osteolytic skeletal metastases remains to be elucidated. Recalcification may also depend on the individual tumor micromilieu and the influence of concurrent systemic treatments. In this context, the patients' age may be an important factor for recalcification of unstable vertebral metastases of various solid tumors. Elderly patients exhibit an increased level of comorbidities that have the potential to influence bone stability and recalcification in the context of bone metastases, among them diabetes mellitus, renal insufficiencies or osteoporosis. Several publications have indicated an influence of bone mineral density and especially osteoporosis on the stability of bone metastases, although no clear evidence is available 
Table 6 Analysis of prognostic factors related to overall survival after palliative RT

\begin{tabular}{|c|c|c|c|c|c|c|}
\hline \multirow[b]{2}{*}{ Predictor } & \multicolumn{3}{|c|}{ Univariate testing } & \multicolumn{3}{|c|}{ Multivariate testing } \\
\hline & $p$-value & HR & $\overline{C I}$ & $p$-value & HR & $\overline{C I}$ \\
\hline Age & 0.197 & 1.017 & $0.991-1.043$ & 0.507 & 1.009 & $0.982-1.038$ \\
\hline $\begin{array}{l}\text { Poorly represented cancers }{ }^{\mathrm{a}} \\
\text { (vs. breast cancer) }\end{array}$ & 0.029 & 1.529 & $1.044-2.240$ & 0.016 & 1.663 & $1.103-2.509$ \\
\hline $\begin{array}{l}\text { Colorectal cancer } \\
\text { (vs. breast cancer) }\end{array}$ & 0.007 & 1.858 & $1.188-2.907$ & NA & 1.548 & $0.879-2.725$ \\
\hline $\begin{array}{l}\text { Renal cancer } \\
\text { (vs. breast cancer) }\end{array}$ & 0.737 & 1.071 & $0.718-1.598$ & NA & 1.116 & $0.665-1.872$ \\
\hline $\begin{array}{l}\text { Lung cancer } \\
\text { (vs. breast cancer) }\end{array}$ & 0.008 & 1.576 & $1.127-2.206$ & NA & 1.602 & $1.133-2.265$ \\
\hline $\begin{array}{l}\text { KPS } \\
(<70 \% \text { vs. } \geq 70 \%)\end{array}$ & $<0.001$ & 0.954 & $0.944-0.964$ & $<0.001$ & 0.953 & $0.942-0.964$ \\
\hline $\begin{array}{l}\text { Chemotherapy } \\
\text { (yes vs. no) }\end{array}$ & 0.151 & 1.177 & $0.943-1.469$ & 0.036 & 1.295 & $1.018-1.647$ \\
\hline $\begin{array}{l}\text { Location } \\
\text { (thoracic vs. lumbar spine) }\end{array}$ & 0.523 & 1.077 & $0.858-1.351$ & 0.664 & 1.054 & $0.832-1.335$ \\
\hline $\begin{array}{l}\text { Number of SBM } \\
(1 \mathrm{vs} .>1)\end{array}$ & 0.004 & 1.066 & $1.021-1.112$ & 0.031 & 1.055 & $1.006-1.107$ \\
\hline $\begin{array}{l}\text { Extraskeletal metastases } \\
\text { (yes vs. no) }\end{array}$ & 0.276 & 1.134 & $0.904-1.423$ & 0.711 & 0.953 & $0.740-1.228$ \\
\hline $\begin{array}{l}\text { Bisphosphonates } \\
\text { (yes vs. no) }\end{array}$ & 0.381 & 0.905 & $0.724-1.131$ & 0.295 & 0.834 & $0.596-1.167$ \\
\hline $\begin{array}{l}\text { Fractures before RT } \\
\text { (yes vs. no) }\end{array}$ & 0.098 & 1.258 & $0.958-1.651$ & 0.383 & 1.138 & $0.853-1.518$ \\
\hline
\end{tabular}

KPS Karnofsky performance score, HR Hazard Ratio, CI Confidence limits of the results for a confidence level of $95 \%$, SBM Spinal bone metastases, $R T$ Radiotherapy, $N A$ not analyzable

a Included SBM of following tumor entities: Malignant melanoma, adenoid cystic carcinoma (ACC), hepatic cell cancer (HCC), head and neck

squamous cell cancer (HNSCC), ovarian cancer, uterine cancer, vulvar cancer, urothelial cancer, prostate cancer

regarding the stabilization rates following palliative RT in these patients $[20,21]$. To the best of our knowledge, no scientific data concerning the stabilization rates have been reported from an explicitly elderly patient cohort, a primary impetus for conducting this retrospective pooled analysis.

Prior to irradiation, $57 \%$ of our study patients exhibited unstable SBM in the thoracic or lumbar spinal column. Within 3 and 6 months after palliative RT, significant recalcification and stabilization were observed in up to $40 \%$ of the analyzed patients still alive at the time of follow-up; a deterioration of stability was measured in only one patient during the follow-up period. The highest stabilization rates in our study population were found in elderly breast cancer patients, while elderly patients with SBM from lung cancer, colorectal cancer, renal cancer or further poorly represented tumor entities such as malignant melanoma, prostate and urothelial cancers showed minor or negligible recalcification following palliative RT. These findings are largely in line with previous published data reporting histology-dependent recalcification in younger patients $[6,15,18,19$, $22]$. Regarding the observed minor stabilization rates in elderly patients with these histologies, alternate approaches for improving the stability of the metastatic vertebral column may need to be considered. Stereotactic ablative ra- diotherapy (SBRT) may hold the potential to increase the stabilization rates in unstable SBM, particularly for geriatric patients with a good performance score and SBM from tumor entities with a relatively low chance of bone stability after 6 months. However, evidence remains to be provided regarding the effectiveness of SBRT for the stabilization of vertebral metastases in elderly patients. Also, surgical stabilization options may become more relevant for the respective patients; however surgery may interrupt necessary systemic treatments for a considerable time compared to SBRT. Additionally, perioperative morbidity and mortality is likely increased in affected geriatric patients.

When interpreting the stabilization rates of our study, it is important to consider the histology-dependent differing prognoses of patients with bone metastases, as significant recalcification after RT requires at least 3 to 6 months. Thus, the relevance of stabilization of unstable SBM is higher for patients with an average survival exceeding 6 months. In our dataset, patients aged 80 years or older showed a strong trend towards reduced survival rates compared to elderly patients below 80 years (i.e., $39 \%$ vs. $51 \%$ at 6 months after $\mathrm{RT} ; p=0.06$ ). This may not only be due to the patients' oncologic outcome, but may also reflect the influence of other age-prevalent causes such as cardiovascular diseases. 
As reported by many studies before, we also found that the performance status was a strong prognostic factor for predicting the residual life expectancy after palliative RT of SBM in elderly patients [23-27]. Here, patients with a KPS below $70 \%$ had an extremely poor overall survival of less than 2 months compared to 9 months for those patients with a KPS of at least $70 \%$. Based on these results, single fraction RT should be the preferred treatment option for elderly patients with a poor general condition and advanced tumor disease, as it has shown equivalent pain control rates compared to more protracted RT schedules [12, 28].

Moreover, our analysis showed that patients with a solitary/singular SBM exhibited an almost doubled median overall survival as compared to patients with 2 or more SBM (7.4 vs. 3.9 months; $p=0.031$ ), while the additional survival benefit by administration of chemotherapy was less than 1 month in these elderly patients ( 5.8 vs. 4.9 months at the median; $p=0.036$ ). The effect of oligometastatic cancers and consecutive ablative treatments in elderly metastatic patients has not yet been elucidated and will likely be subject to further research in the future.

Our study has some limitations, especially the retrospective character of this patient cohort. For instance, comorbidities (including age- and cancer therapy-related osteoporosis), the patients' smoking status, medications and lifestyle factors such as physical exercises could not be routinely assessed in our elderly patient cohort, although it is conceivable that these factors might have an impact on the stabilization and fracture rates after palliative RT as well as overall survival. Second, the used Taneichi score is restricted to score the stability of osteolytic thoracic and lumbar metastases. As a consequence, prostate cancer patients are considerably underrepresented in this elderly cohort, as the majority of SBM from prostate cancer has an osteoplastic phenotype. Since the majority of SBM spread to the thoracic and lumbar spine, we believe that the nonconsideration of the cervical and sacral spine represents only a minor limitation. A third limitation is due to the long inclusion time period, many patients in our study were treated before modern systemic therapies such as targeted therapies and checkpoint inhibitors became routinely used in the clinic. While these agents substantially contributed to improved survival times in many metastatic tumor diseases in recent years, their routine use in geriatric patients remains subject to some debate [29-33]. On the other hand, the stabilization effect of palliative radiotherapy in unstable SBM might become better than reported in this study with improved overall survival rates. Nevertheless, results from this large multicenter cohort of patients with an advanced age help to generate hypotheses that may direct further assessment of palliative radiation effects through prospective clinical trials in elderly patients, and these trials are urgently required to address the palliative needs of an increasingly aging population.

\section{Conclusion}

The treatment of elderly patients with unstable SBM is complex and requires a multidisciplinary approach whereby palliative RT has a pivotal role in the treatment concept. Histology and performance status seem to dominate prognosis of elderly patients with SBM and should be considered to determine radiation fractionation in order to reduce hospitalization times in the remaining lifespan.

\section{Compliance with ethical guidelines}

Conflict of interest T. Bostel, R. Förster, I. Schlampp, T. Sprave, S. Akbaba, D. Wollschläger, J. Debus, A. Mayer, H. Schmidberger, H. Rief and N.H. Nicolay declare that they have no competing interests.

Ethical standards All studies on humans described in the present manuscript were carried out with the approval of the responsible ethics committees and in accordance with national law and the Helsinki Declaration of 1975 (in its current, revised form).

Open Access This article is distributed under the terms of the Creative Commons Attribution 4.0 International License (http:// creativecommons.org/licenses/by/4.0/), which permits unrestricted use, distribution, and reproduction in any medium, provided you give appropriate credit to the original author(s) and the source, provide a link to the Creative Commons license, and indicate if changes were made.

\section{References}

1. Vineis P, Wild CP (2014) Global cancer patterns: causes and prevention. Lancet 383:549-557

2. Marosi C, Koller M (2016) Challenge of cancer in the elderly. Esmo Open 1:e20

3. Aebi M (2003) Spinal metastasis in the elderly. Eur Spine $\mathbf{J}$ 12(Suppl 2):S202-S213

4. Guise TA (2006) Bone loss and fracture risk associated with cancer therapy. Oncologist 11:1121-1131

5. Schlampp I, Rieken S, Habermehl D et al (2014) Stability of spinal bone metastases in breast cancer after radiotherapy: a retrospective analysis of 157 cases. Strahlenther Onkol 190:792-797

6. Rief H, Bischof M, Bruckner T et al (2013) The stability of osseous metastases of the spine in lung cancer-a retrospective analysis of 338 cases. Radiat Oncol 8:200

7. Chow S, Ding K, Wan BA et al (2017) Patient reported outcomes after radiation therapy for Bone metastases as a function of Age: a secondary analysis of the NCIC CTG SC-twenty-three randomized trial. Am J Hospice Palliat Med 35(4):718-723

8. Nieder C, Angelo K, Haukland E, Pawinski A (2014) Survival after palliative radiotherapy in geriatric cancer patients. Anticancer Res 34:6641-6645

9. Rades D, Conde AJ, Garcia R et al (2015) A new instrument for estimation of survival in elderly patients irradiated for metastatic spinal cord compression from breast cancer. Radiat Oncol 10:173

10. Rades D, Evers JN, Rudat V, Bajrovic A, Karstens JH, Schild SE (2014) A validated score estimating ambulatory status following 
radiotherapy of elderly patients for metastatic spinal cord compression. BMC Cancer 14:589

11. Nakamura N, Shikama N, Wada H et al (2012) Patterns of practice in palliative radiotherapy for painful bone metastases: a survey in Japan. Int J Radiat Oncol Biol Phys 83:e117-20

12. Chow E, Harris K, Fan G, Tsao M, Sze WM (2007) Palliative radiotherapy trials for bone metastases: a systematic review. J Clin Oncol 25:1423-1436

13. Lutz S, Berk L, Chang E et al (2011) Palliative radiotherapy for bone metastases: an ASTRO evidence-based guideline. Int J Radiat Oncol Biol Phys 79:965-976

14. Taneichi H, Kaneda K, Takeda N, Abumi K, Satoh S (1997) Risk factors and probability of vertebral body collapse in metastases of the thoracic and lumbar spine. Spine 22:239-245

15. Bostel T, Forster R, Schlampp I et al (2017) Spinal bone metastases in colorectal cancer: a retrospective analysis of stability, prognostic factors and survival after palliative radiotherapy. Radiat Oncol 12:115

16. Sprave T, Hees K, Bruckner T et al (2018) The influence of fractionated radiotherapy on the stability of spinal bone metastases: a retrospective analysis from 1047 cases. Radiat Oncol 13:134

17. Foerster R, Habermehl D, Bruckner T et al (2014) Spinal bone metastases in gynecologic malignancies: a retrospective analysis of stability, prognostic factors and survival. Radiat Oncol 9:194

18. Foerster R, Hees K, Bruckner T et al (2018) Survival and stability of patients with Urothelial cancer and spinal Bone metastases after palliative radiotherapy. Radiol Oncol 52:189-194

19. Bostel T, Forster R, Schlampp I et al (2016) Stability, prognostic factors and survival of spinal bone metastases in malignant melanoma patients after palliative radiotherapy. Tumori 102:156-161

20. Salvatore G, Berton A, Giambini $\mathrm{H}$ et al (2018) Biomechanical effects of metastasis in the osteoporotic lumbar spine: a finite element analysis. BMC Musculoskelet Disord 19:38

21. Pagani S, Fini M, Giavaresi G, Salamanna F, Borsari V (2015) The active role of osteoporosis in the interaction between osteoblasts and bone metastases. Bone 79:176-182

22. Schlampp I, Lang H, Forster R et al (2015) Stability of spinal bone metastases and survival analysis in renal cancer after radiotherapy. Tumori 101:614-620
23. Bollen L, Jacobs WCH, Van der Linden YM, Van der Hel O, Taal W, Dijkstra PDS (2018) A systematic review of prognostic factors predicting survival in patients with spinal bone metastases. Eur Spine J 27:799-805

24. Bollen L, van der Linden YM, Pondaag W et al (2014) Prognostic factors associated with survival in patients with symptomatic spinal bone metastases: a retrospective cohort study of 1,043 patients. Neuro-oncology 16:991-998

25. Westhoff PG, de Graeff A, Monninkhof EM et al (2014) An easy tool to predict survival in patients receiving radiation therapy for painful bone metastases. Int J Radiat Oncol Biol Phys 90:739-747

26. van der Linden YM, Dijkstra SP, Vonk EJ, Marijnen CA, Leer JW, Dutch Bone Metastasis Study Group (2005) Prediction of survival in patients with metastases in the spinal column: results based on a randomized trial of radiotherapy. Cancer 103:320-328

27. Rades D, Evers JN, Bajrovic A, Veninga T, Karstens JH, Schild SE (2014) Metastatic spinal cord compression: a validated survival score for elderly patients. Strahlenther Onkol 190:919-924

28. Koswig S, Budach V (1999) Remineralization and pain relief in bone metastases after after different radiotherapy fractions (10 times $3 \mathrm{~Gy}$ vs. 1 time $8 \mathrm{~Gy}$ ). A prospective study. Strahlenther Onkol 175:500-508

29. Weber JS, D'Angelo SP, Minor D et al (2015) Nivolumab versus chemotherapy in patients with advanced melanoma who progressed after anti-CTLA-4 treatment (CheckMate 037): a randomised, controlled, open-label, phase 3 trial. Lancet Oncol 16:375-384

30. Herbst RS, Baas P, Kim DW et al (2016) Pembrolizumab versus docetaxel for previously treated, PD-L1-positive, advanced nonsmall-cell lung cancer (KEYNOTE-010): a randomised controlled trial. Lancet 387:1540-1550

31. Hodi FS, O'Day SJ, McDermott DF et al (2010) Improved survival with ipilimumab in patients with metastatic melanoma. $\mathrm{N}$ Engl $\mathrm{J}$ Med 363:711-723

32. Elias R, Giobbie-Hurder A, McCleary NJ, Ott P, Hodi FS, Rahma O (2018) Efficacy of PD-1 \& PD-L1 inhibitors in older adults: a metaanalysis. J Immunother Cancer 6:26

33. Daste A, Domblides C, Gross-Goupil M et al (2017) Immune checkpoint inhibitors and elderly people: A review. Eur J Cancer $82: 155-166$ 